\title{
EDITORIAL EDITORIAL
}

A partir desse ano o Fórum Nacional de Pesquisa e Pós-Graduação Stricto Sensu em Fisioterapia, promovido Associação Brasileira de Pesquisa e Pós-graduação em Fisioterapia - ABRAPG-FT volta a ser anual e será organizado e sediado pelo Curso de Fisioterapia da Faculdade de Medicina de Ribeirão Preto/USP. Trata-se do VI Fórum que ocorrerá entre os dias 11 e 13 de maio, com o objetivo de reunir os pesquisadores e alunos dos programas de pós-graduação da área de fisioterapia e reabilitação, para discutir as fontes de fomento, as propostas de projetos multicênticos nas áreas Musculoesquelética, Neurologia e Cardiorrespiratória, bem como os periódicos da área, com a participação do prof. Dr. CHRISTOPHER G. MAHER do Centre for Evidence-Based Physiotherapy, Musculoskeletal Division, University of Sydney.

O crescimento dos programas de pós-graduação, aferido pelas CAPES nesse último triênio, bem como o crescimento do número de pesquisadores doutores com graduação em Fisioterapia na última década foi expressivo. Esses números mostram que a produção do conhecimento e a formação de recursos humanos na Área cresceu e que necessita, cada vez mais, de planejamento estratégico para definir os seus interesses e prioridades.

As ações decorrentes das discussões ocorridas nos Fóruns anteriores tem propiciado uma maior interação dos pesquisadores com as agências de fomento, bem como com os representantes das áreas para o desenvolvimento de políticas que possam incentivar a abertura de novos programas, bem como consolidar os já existentes. A constituição desses grupos deve emergir do interesse comum por alguma interface da fisioterapia, mantendo-se em redes de comunicação, favorecendo assim, a identificação e articulação com outros pesquisadores e instituições que mantém interesses similares de estudo, facilitando a celebração de convênios, intercâmbios.

Visando facilitar as parcerias, a ABRAPG-Ft convida a todos para participarem do VI Fórum Nacional de Pesquisa e Pós-graduação em Fisioterapia que ocorrerá no Bloco Didático da Faculdade de Medicina de Ribeirão Preto/USP, no período de 11 a 13 de maio de 2011, onde serão apresentados, dentre outros temas, projetos de estudos multicêntricos com vistas à formação de grupos de pesquisa.

Uma associação só é forte se for representativa e com associados atuantes. Para que isso se concretize, necessitamos da participação de todos no VI Fórum, motivo pelo qual o convidamos a visitar a home-page da associação (www.abrapg-ft.org.br) e se inscrever para o evento.

Aguardamos todos em Ribeirão Preto/SP.

Comissão Organizadora do VI Fórum da ABRAPG-FT

Rinaldo Roberto de J. Guirro

Editor-chefe 